\title{
Emergency Department Visits for Behavioral and Mental Health Care After a Terrorist Attack
}

\section{Charles DiMaggio, PhD, MPH, \\ PA-C}

Sandro Galea, MD, DrPH

Lynne D. Richardson, MD
From the Department of Epidemiology, Columbia University, Mailman School of Public Health, New York, NY (DiMaggio); the Department of Epidemiology, University of Michigan School of Public Health, Ann Arbor, MI (Galea); and the Department of Emergency Medicine, The Mount Sinai School of Medicine, New York, NY (Richardson).

Study objective: We assess emergency department (ED) utilization by a population whose health care encounters can be tracked and quantified for behavioral and mental health conditions in the aftermath of the terrorist attacks of September 11, 2001.

Methods: We assessed presentations to EDs by using Medicaid analytic extract files for adult New York State residents for 2000 and 2001. We created 4 mutually exclusive geographic areas that were progressively more distant from the World Trade Center and divided data into 4 periods. All persons in the files were categorized by their zip code of residence. We coded primary ED diagnoses for posttraumatic stress disorder, substance abuse, psychogenic illness, severe psychiatric illness, depression, sleep disorders, eating disorders, stress-related disorders, and adjustment disorders.

Results: There was a $10.1 \%$ relative temporal increase in the rate of ED behavioral and mental health diagnoses after the September 11, 2001, terrorist attacks for adult Medicaid enrollees residing within a 3-mile radius of the World Trade Center site. Other geographic areas experienced relative declines. In population-based comparisons, Medicaid recipients who lived within 3 miles of the World Trade Center after the September 11, 2001, terrorist attacks had a $20 \%$ increased risk of an ED mental health diagnosis (prevalence density ratio 1.2; 95\% confidence interval 1.1 to 1.3) compared to those who were non-New York City residents.

Conclusion: The complex role that EDs may play in responding to terrorism and disasters is becoming increasingly apparent. To the best of our knowledge, this is the first report of a quantifiable increase in ED utilization for mental health services by persons exposed to a terrorist attack in the United States. [Ann Emerg Med. 2007;50:327-334.]

\section{INTRODUCTION}

\section{Background}

The behavioral consequences of terrorist incidents have received considerable recent attention, much of it driven by the 1995 Oklahoma City bombings, the terrorist attacks of September 11, 2001, in the United States, and the more recent Madrid 2004 and London 2005 bombings. A recent metaanalysis of terrorism-related mental health disturbance found that in the year after a terrorist incident, posttraumatic stress disorder prevalence in directly affected populations varies between $12 \%$ and $16 \%{ }^{1}$

The September 11, 2001, terrorist attacks are probably the single most studied terrorist attack in history. ${ }^{1}$ In the first 2 months after the September 11 attacks, studies showed that $7.5 \%$ of persons living in Manhattan reported symptoms consistent with posttraumatic stress disorder. ${ }^{2}$ Twenty percent of New York City residents living below Canal Street, in close proximity to the events, met the criteria for posttraumatic stress disorder. ${ }^{3}$ Anxiety-related symptoms were reported by almost $50 \%$ of the population of New York City's Chinatown, which is located in the immediate vicinity of the World Trade Center, ${ }^{4}$ as was an increased self-reported need for psychiatric and emergency care, ${ }^{5,6}$ a high prevalence of use of free mental health services established by public health authorities, ${ }^{7-10}$ and a potential increase in stress-related cardiac events. ${ }^{11}$ Distress was reported among individuals far removed from the events. ${ }^{12}$ There have been suggestions that there were unmet mental health needs in the immediate aftermath of the attacks. ${ }^{13}$

Despite this evidence, it is less clear that increased mental and behavioral health disorders in the population translated into 


\section{Editor's Capsule Summary}

What is already known on this topic

Natural disasters, terrorist attacks, and other mass traumatic events can increase mental health problems in the affected population.

\section{What question this study addressed}

Did emergency department (ED) visits by Medicaid enrollees for mental health problems increase in the New York metropolitan area after the September 11, 2001, terrorist attack?

What this study adds to our knowledge

This study demonstrates that the number of ED visits resulting in a psychobehavioral diagnosis increased by $10 \%$ for the 3 months after September 11 for Medicaid enrollees who lived within 3 miles of the World Trade Center. ED visits resulting in mental health diagnoses decreased somewhat for Medicaid enrollees who lived farther away.

How this might change clinical practice

EDs in close proximity to a major disaster should prepare for an increase in mental health needs after the event.

increased health service use. Although one Department of Veterans Affairs analysis found a small but significant increase in service use for posttraumatic stress disorder in New York and New Jersey after the terrorist attacks of September 11, 2001, ${ }^{14}$ others found no significant increase in the use of mental health services for the treatment of posttraumatic stress disorder among military veterans in the New York City area. ${ }^{15}$ Nationally, those treated in a Department of Veterans Affairs posttraumatic stress disorder program in the 6 months after the September 11 attacks did not have significantly worse symptomology compared with the 6 months before the attack. ${ }^{16}$ These studies led one observer to comment that the expected mental health crisis after the September 11,2001 , terrorist attacks had failed to materialize. ${ }^{17}$

\section{Importance}

The relatively few studies of emergency department (ED) utilization after the terrorist attacks of September 11, 2001, have focused on physical injuries such as ocular and orthopedic trauma, health-related quality of life, and asthma. ${ }^{18-20} \mathrm{No}$ study, to our knowledge, has addressed the role EDs may have played in providing mental or behavioral health care.

\section{Goals of This Investigation}

We assess ED utilization for behavioral and mental health conditions in the aftermath of the terrorist attacks of September 11,2001 . Studies that examined primarily inpatient data may not have captured the outpatient experience of New York City residents. The city's EDs, in addition to providing the majority of trauma care, were likely also a setting for behavioral health care after the terrorist attacks of September 11, 2001. We hypothesized an increase in ED visits for behavioral and mental health diagnoses for persons who resided closest to the site of the World Trade Center compared to those residing outside of New York City.

\section{MATERIALS AND METHODS Study Design}

We conducted a retrospective analysis of Medicaid analytic extract files data for adult New York State residents for 2000 and $2001 .^{21}$ These are a complete set of person-level data files on all New York State residents who received Medicaid-funded inpatient and outpatient, including ED, services.

The data files are compiled by the Centers for Medicare and Medicaid Services from claim information provided by the New York State Department of Health. Health care providers submit standardized claims ${ }^{22}$ that include clinical information that is most commonly abstracted from patient medical records by nonclinician administrative personnel. The Centers for Medicare and Medicaid Services routinely conducts validation studies of Medicaid analytic extract data, ${ }^{23}$ and researchers have analyzed and validated the reliability of these data for studies of outpatient psychiatric diagnoses in New York State. ${ }^{24}$

\section{Setting}

According to separate spatial analyses and published reports, ${ }^{2,4}$ we created 4 mutually exclusive geographic areas that were progressively more distant from the World Trade Center. The first area included all geographic zip code tabulation areas whose centroids were contained within a 3-mile radius of a centroid located in the 10007 zip code tabulation area that corresponded to the intersection of Church and Vesey Streets in lower Manhattan, where the World Trade Center complex was located. The second area consisted of zip code tabulation areas greater than 3 miles but 10 or fewer miles from the World Trade Center. The third area consisted of zip code tabulation areas greater than 10 miles but within the geographic confines of New York City. The fourth area was made up of all nonNew York City zip code tabulation areas in New York State. All persons in the database for whom a zip code was available were geocoded to one of these 4 areas.

We established 4 periods for analysis: the week beginning January 1, 2000, to the week ending September 16, 2000; the week beginning September 17, 2000, until the week ending December 30, 2000; the week beginning December 31, 2000, to the week ending September 15, 2001; and the week beginning September 16, 2001, to the week ending December 29, 2001. Given that data from 2002 have not yet been released by the Centers for Medicare and Medicaid Services, we chose the dates to capture the post-September 11, 2001, period for the 2 available years, establishing equally sized periods for comparisons from one year to the next. For ease of description, we refer to these periods as period 1 , period 2 , period 3 , and period 4 . 


\section{Selection of Participants}

We used a "place of service" variable to identify ED visits from among all New York State Medicaid analytic extract outpatient data service files for 2000 and 2001. The study data set then consisted of all Medicaid-funded ED visit records in New York State in 2000 and 2001. These records were separate from and mutually exclusive of inpatient services, including inpatient psychiatric services. ${ }^{25,26}$

Duplicate records were removed according to patient identification number, date of visit, and diagnosis. This process did not remove records for visits with the same diagnosis on different dates that were accepted by Medicaid as separate billable visits. We created a variable to identify behavioral and mental-health-related primary diagnoses from the following International Classification of Diseases, Ninth Revision, Clinical Modification ${ }^{27}$ codes and their associated relevant subcodes: posttraumatic stress disorder (309), substance abuse (291, 292, $303,304,305)$, psychogenic illness $(306,307)$, severe psychiatric illness $(295,296,297,298)$, depression $(309,313)$, sleep disorders (307), eating disorders (307), stress-related disorders (308), and adjustment disorders (309). Categorization was based on the first (primary) diagnosis on the record.

\section{Primary Data Analysis}

We tabulated information on patient identifiers, demographics, eligibility status by month, and diagnosis. For each geographic area and for each period, we calculated the mean age and frequency of sex and race/ethnicity of Medicaid enrollees receiving ED services. We compared results across time and geographic area with analysis of variance by using the Tukey correction for continuous variables and $\chi^{2}$ for categorical variables.

For each period and geographic area, we used a Poisson regression model to estimate the risk of an individual's receiving an ED diagnosis of a behavioral or mental health disorder. Our modeling strategy consisted of plotting the outcome variable (behavioral and mental health diagnosis counts) to ensure a nonnegative, skewed, rare distribution consistent with a Poisson process. We graphed bar charts of categorical variables (sex and race/ethnicity) and smoothed splines of continuous variables (age) against the outcome variable to test linearity assumptions. The final model included sex, race/ethnicity, and age group (21 to 44 and 45 to 64 years) as categorical variables. To control for the population at risk, the Poisson regression model included an offset variable based on the log of the total number of person-days of Medicaid eligibility in each period and geographic location. Each individual who visited an ED contributed the number of days they were eligible for Medicaid benefits to a total for the geographic area for the period under study. Using the experience of individuals residing outside New York City as the referent category, the results are interpreted as prevalence ratios.

Analyses were conducted using SAS version 9.1 (SAS Institute, Inc., Cary, NC) and its associated GENMOD procedure. The study protocol was approved by the Columbia University institutional review board.

\section{RESULTS}

\section{Characteristics of Study Subjects}

There were 1,229,462 ED visits by adult New York State Medicaid enrollees between the ages of 21 and 64 years during the 2-year study period. Full demographic details are in Table 1. Within the 21- to 64-year-old group defined for the study, there was no clinically meaningful difference in mean age across periods or geographic areas. Also, within this 21- to 64-year-old group are a greater proportion of male enrollees who lived within 3 miles of the World Trade Center site (51.9\%) compared to those who lived outside of New York City (43.3\%) during period 4 (difference $=8.6$; $95 \%$ confidence interval $[\mathrm{CI}]$ 7.6 to 9.8). There were similar sex differences for all the periods.

New York City enrollees who visited EDs were, on average, more ethnically and racially diverse than non-New York City enrollees who visited EDs. During period 4, there were 36.9\% (95\% CI 35.9 to 38.0) fewer white enrollees among ED visitors who lived within 3 miles of the World Trade Center site compared to those who lived outside of New York City and $11.6 \%$ (95\% CI 10.7 to 12.5 ) more black and $11.9 \%$ (95\% CI 11.3 to 12.5 ) more Hispanic ED visitors (Table 1). There was little or no meaningful difference in the proportion of Asian ED visitors across periods and geographic areas. The high proportion of Asian enrollees among ED visitors in the area within 3 miles of the World Trade Center site is consistent with US census-based reports of the demographic characteristics of lower Manhattan. ${ }^{28}$

\section{Main Results}

Of the total sample of ED visits, 69,345 (5.6\%) received primarily mental or behavioral health diagnoses. For the entire study period, the 2 most frequent diagnostic categories within this group were a constellation of diagnoses we termed "severe psychiatric disease," which consisted of schizophrenia, mania, bipolar disorder and psychosis (56.1\%), and substance abuse (40.1\%). Posttraumatic stress disorder accounted for $0.2 \%$ of behavioral and mental health diagnoses. For the entire study period, substance abuse accounted for a greater proportion of ED mental health and behavioral diagnoses for Medicaid enrollees residing within a 3-mile radius of the World Trade Center site (58.1\%) than for those living outside of New York City $(28.3 \%)$ (difference $=29.4 ;$; 95\% CI 28 to 30.9 ). Conversely, relatively fewer ED mental health diagnoses were for severe psychiatric disease for residents within 3 miles of the site $(38.7 \%)$ than for those living outside of the city $(67.2 \%)$ (difference $=28.5 ; 95 \%$ CI 26.9 to 29.9).

Compared to the previous 9 months (period 3), in the 3 -month period after the terrorist attacks of September 11, 2001 (period 4), there was a $10.1 \%$ relative increase in the rate of ED behavioral and mental health diagnoses for adult Medicaid enrollees visiting EDs and residing within a 3-mile radius of the World Trade Center site. The other geographic 
Table 1. Mean age (SD) and percentage of sex, race/ethnicity of New York State Medicaid recipients, aged 21 to 64 years, receiving ED services, by geographic zone and period (New York State Medicaid data 2000 to 2001).*

\begin{tabular}{|c|c|c|c|c|}
\hline \multirow[b]{2}{*}{ Race/Ethnicity } & \multicolumn{4}{|c|}{ Residence in Relation to World Trade Center Site } \\
\hline & $<3$ Miles & 3-10 Miles & New York City $>10$ Miles & Non-New York City \\
\hline \multicolumn{5}{|c|}{ Sept. 2001-Dec. 2001} \\
\hline ED visits & $N=15,096$ & $N=108,924$ & $N=123,279$ & $N=146,801$ \\
\hline Age, y & $44.1(11.1)$ & $43.6(12.1)$ & $43.6(12.1)$ & $42.3(11.9)$ \\
\hline Female & 48.0 & 59.9 & 60.9 & 56.7 \\
\hline White & 18.5 & 16.9 & 16.0 & 55.4 \\
\hline Black & 30.7 & 32.3 & 25.6 & 19.1 \\
\hline American Indian & 0.7 & 0.9 & 0.9 & 0.5 \\
\hline Asian & 0.9 & 1.6 & 2.0 & 0.7 \\
\hline Hispanic & 19.8 & 19.7 & 26.2 & 7.9 \\
\hline Unknown/other & 29.5 & 28.8 & 29.2 & 16.4 \\
\hline \multicolumn{5}{|c|}{ Jan. 2001-Aug. 2001} \\
\hline ED visits & $N=38,234$ & $N=255,182$ & $N=293,591$ & $N=351,485$ \\
\hline Age, y & $44.6(11.1)$ & $44.2(12.0)$ & $43.7(12.1)$ & $42.4(11.9)$ \\
\hline Female & 45.9 & 59.1 & 62.1 & 56.6 \\
\hline White & 18.2 & 17.8 & 16.9 & 54.8 \\
\hline Black & 30.3 & 34.3 & 27.5 & 19.4 \\
\hline American Indian & 0.9 & 0.9 & 0.9 & 0.5 \\
\hline Asian & 1.0 & 1.7 & 2.2 & 0.6 \\
\hline Hispanic & 22.6 & 22.4 & 29.8 & 8.9 \\
\hline Unknown/other & 26.9 & 22.9 & 22.7 & 15.6 \\
\hline \multicolumn{5}{|c|}{ Sept. 2000-Dec. 2000} \\
\hline ED visits & $N=14,670$ & $N=92,727$ & $N=106,444$ & $\mathrm{~N}=117,819$ \\
\hline Age, y & $45.8(11.1)$ & $45.3(12.0)$ & $45.0(12.0)$ & $43.1(11.8)$ \\
\hline Female & 46.2 & 59.5 & 62.1 & 56.9 \\
\hline White & 16.8 & 16.6 & 16.2 & 55.5 \\
\hline Black & 29.7 & 32.4 & 25.5 & 18.5 \\
\hline American Indian & 0.5 & 0.7 & 0.7 & 0.5 \\
\hline Asian & 1.2 & 1.6 & 1.8 & 0.6 \\
\hline Hispanic & 22.6 & 25.1 & 31.5 & 8.5 \\
\hline Unknown/other & 29.1 & 23.7 & 24.2 & 16.4 \\
\hline \multicolumn{5}{|c|}{ Jan. 2000-Aug. 2000} \\
\hline ED visits & $N=35,993$ & $N=229,609$ & $N=251,908$ & $N=320,190$ \\
\hline Age, y & $45.6(11.3)$ & $45.0(12.0)$ & $44.9(12.0)$ & $43.2(11.7)$ \\
\hline Female & 47.2 & 59.2 & 61.6 & 56.8 \\
\hline White & 16.5 & 15.7 & 14.9 & 55.5 \\
\hline Black & 28.9 & 32.0 & 26.3 & 18.3 \\
\hline American Indian & 0.6 & 0.4 & 0.5 & 0.5 \\
\hline Asian & 1.2 & 1.6 & 1.7 & 0.6 \\
\hline Hispanic & 23.6 & 25.4 & 32.3 & 8.8 \\
\hline Unknown/other & 29.3 & 24.7 & 24.1 & 16.6 \\
\hline
\end{tabular}

areas experienced relative decreases of $11.7 \%$ (residing 3 to 10 miles from the World Trade Center), 5.8\% (residing $>10$ miles from World Trade Center but within New York City), and $3.6 \%$ (non-New York City residents) $\left(\chi^{2}=23.1 ; 3 d f\right.$; $P<.0001)$. There were no comparable changes in the rates of mental and behavioral health diagnoses from period 1 to period 2 (Table 2 ).

In Poisson regression analyses controlling for age, sex, and race with Medicaid enrollees who visited EDs who resided outside New York City as the referent category, the incidence density ratio for ED behavioral and mental health diagnoses was 1.2 (95\% CI 1.1 to 1.3 ) during period 4 for Medicaid enrollees residing within 3 miles of the World Trade Center. No similar increased risk was observed in residents living within 3 miles of the World Trade Center before September 11, 2001, nor was there a comparable increased risk after the terrorist attacks of September 11, 2001, in other geographic areas (Table 3).

\section{LIMITATIONS}

Medicaid is a federal, state, and-in New York State-locally funded health insurance program with locally determined income, age, and disability requirements. While the reliability of using Medicaid databases for analyzing mental health diagnoses ${ }^{24}$ has been validated, this vulnerable group 
Table 2. Rate per 100 person-years of eligibility for ED behavioral and mental health diagnoses, New York State Medicaid recipients aged 21 to 64 years, who visited EDs, by geographic zone in relation to World Trade Center site and period (New York State Medicaid MAX data 2000 to 2001).*

\begin{tabular}{lcccc}
\hline & \multicolumn{4}{c}{ Residence in Relation to World Trade Center Site } \\
\cline { 2 - 5 } Period & < $\mathbf{3}$ Miles & $\mathbf{3 - 1 0}$ Miles & New York City $>$ 10 Miles & Non-New York City \\
\hline Sept. 2001-Dec. 2001 & 97.4 & 46.2 & 55.1 & 82.5 \\
Jan. 2001-Aug. 2001 & 88.5 & 52.3 & 58.5 & 85.6 \\
Sept. 2000-Dec. 2000 & 79.8 & 45.0 & 47.2 & 83.5 \\
Jan. 2000-Aug. 2000 & 80.5 & 51.1 & 53.7 & 88.3
\end{tabular}

*The week beginning January 1, 2000, to the week ending September 16, 2000; the week beginning September 17, 2000, until the week ending December 30, 2000; the week beginning December 31, 2000, to the week ending September 15, 2001; and the week beginning September 16 , 2001, to the week ending December 29, 2001.

Table 3. Incidence density ratios and $95 \% \mathrm{Cl}$ for ED diagnoses of behavioral or mental health disorder in Medicaid recipients aged 21 to 64 years, who visited EDs, by period and geographic area of residence in relation to World Trade Center site (nonNew York City residents as referent category), controlling for age, sex, and race.*

\begin{tabular}{lcccc}
\hline & \multicolumn{3}{c}{ Residence in Relation to World Trade Center Site } \\
\cline { 2 - 5 } Period & $<$ Miles & 3-10 Miles & New York City >10 Miles & $\begin{array}{c}\text { Non-New York City } \\
\text { (Referent Category) }\end{array}$ \\
\hline Sept. 2001-Dec. 2001 & $1.2(1.1-1.3)$ & $0.7(0.6-0.7)$ & $0.8(0.7-0.8)$ & 1.0 \\
Jan. 2001-Aug. 2001 & $1.0(1.0-1.1)$ & $0.7(0.6-0.7)$ & $0.8(0.7-0.8)$ & 1.0 \\
Sept. 2000-Dec. 2000 & $0.9(0.8-1.0)$ & $0.6(0.6-0.7)$ & $0.7(0.6-0.7)$ & 1.0 \\
Jan. 2000-Aug. 2000 & $0.9(0.9-1.0)$ & $0.6(0.6-0.7)$ & $0.7(0.6-0.7)$ & 1.0
\end{tabular}

*The week beginning January 1, 2000, to the week ending September 16, 2000; the week beginning September 17, 2000, until the week ending December 30, 2000; the week beginning December 31, 2000, to the week ending September 15, 2001; and the week beginning September 16 , 2001 , to the week ending December 29, 2001.

differs from the general population in ways that affect their health and medical care utilization ${ }^{29}$ and that make them more likely to have mental illness. ${ }^{30}$

In response to communication and computer infrastructure disruptions after the terrorist attacks of September 11, 2001, program officials implemented the Disaster Medicaid Relief program. Participants received 4 months of coverage based on a simplified 1-page application. Enrollments began 2 weeks after the terrorist attacks of September 11, 2001. The enrollment period ran for the 4-month period from October 2001 to the end of January 2002. ${ }^{31}$ The 342,362 persons who enrolled in Disaster Medicaid Relief represented a $12 \%$ increase in the 2.85 million preexisting enrollees. ${ }^{32}$ Forty-four percent of these individuals transitioned to the regular Medicaid program at the end of 4 months. It is therefore possible that some of the increased post-September 11 use can explained, in part, by the wider availability of free services to Disaster Medicaid Relief.

We could not identify the records of individuals enrolled as part of Disaster Medicaid Relief but attempted to control for this shift in the number of eligible individuals by basing our use rates on person-years of Medicaid eligibility. This approach should have controlled for the increased number of eligible individuals by including them in the denominator of our rates. We also controlled for potential changes in the social and demographic characteristics of the population under study that may have been due to secular changes caused by time or trends or to movement of persons out of New York City after the terrorist attacks. That the increases were limited to those individuals who lived closest to the World Trade Center lends further credence to our results. Although our results cannot attribute causation, they are consistent with our knowledge about the increase in mental health pathology after terrorism and have the strength of a plausible exposure effect.

Our results are applicable only to adults. We chose to restrict our analyses to an adult population for a number of reasons. Providing care for the emergency health needs of children differs in many respects from caring for adults, and we believe they deserve separate consideration that accounts for and focuses on their unique characteristics. ${ }^{33}$ There are, additionally, 2 aspects of care for the elderly that may present unique biases when Medicaid data are analyzed. One is the complexity of crosscoverage through Medicare. The other is the phenomenon of otherwise well-off elderly "spending down" to qualify for Medicaid long-term care services. This would, again, represent a markedly different population.

Although a provider identification number is listed for each service record, the database to identify providers is privileged information. As such, we could not determine whether diagnoses were made by emergency physicians, psychiatrists, or other clinicians. 
Finally, we examined only 3 months of postattack data. New York Medicaid analytic extract files for 2002 have not yet been released by the Centers for Medicaid Services. ${ }^{34}$ There is, though, evidence that the largest mental health effects such as posttraumatic stress disorder occur within 2 months of an incident. ${ }^{1}$ Still, future analysis must assess whether the increased ED utilization among nearby residents of the World Trade Center area was short lived or sustained.

\section{DISCUSSION}

Although it is increasingly clear that the terrorist attacks of September 11, 2001, had a deleterious effect on the mental and behavioral health of New Yorkers, ${ }^{2-9}$ it has been less evident that this increased need translated into increased use of services. ${ }^{15,16,35}$ Our analyses add to the evidence that the mental and behavioral health disturbances after the terrorist attacks prompted individuals to seek care $\mathrm{r}^{7,36}$ and, for the first time, suggest that EDs played an important role in providing that care.

Mental health care use after crises such as disasters and terrorist attacks is difficult to measure. Service may be disrupted and administrative functions curtailed. Fear of violence may cause people to stay home. ${ }^{37}$ Psychiatric conditions may present as or be overshadowed by physical complaints, ${ }^{38}$ which may help explain some of the discrepancy between population-based surveys documenting high prevalence of psychopathology and health service use studies that show minimal increase in service use after such incidents.

Our results indicate that after the terrorist attacks of September 11, 2001, outpatient service utilization, particularly in EDs, may have differed from inpatient and specialty service utilization. The diagnosable mental health conditions presenting to health care providers after terrorist attacks may not increase to the level of a need for admission but may nonetheless be of sufficient distress to motivate an individual to seek emergency care.

The increasing volume of ED visits for the care of acute illness and injuries has been well documented, and there is a growing appreciation for the multiple and essential roles of the ED within the US health care system. ${ }^{39-42}$ The role of the $\mathrm{ED}$ in the nation's health care safety net, the central role of emergency personnel in the immediate response to masscasualty incidents, and the emerging role of ED data in disease detection and surveillance have all been described. ${ }^{43-45}$

ED utilization presents a unique window into population health after a disaster. ${ }^{46}$ Our findings speak to unmet mental health needs after disasters ${ }^{13}$ and the role EDs may be expected to play in meeting them. Reports from New Orleans suggest a significant impact of the post-Katrina closing of Charity Hospital's ED on the availability of mental health services to vulnerable populations. ${ }^{47}$ Our study of a similarly vulnerable Medicaid population is consistent with these reports.

Our findings are in contrast to a well-conducted report of little or no increased psychotropic medication use among a group of employed insurance plan members affected by the terrorist attacks. ${ }^{35}$ We suspect that this difference may be due in part to a "healthy worker effect." Our population of Medicaid enrollees would be expected to have a high proportion of unemployed and underemployed individuals and would likely be less healthy overall than a group of employed persons. Low socioeconomic status and unemployment are risk factors for mental health pathology after mass trauma. ${ }^{48,49}$ It is possible that a postterrorism epidemiologic analysis of employed insurance beneficiaries is less likely than one conducted on a group of Medicaid enrollees to demonstrate increased psychiatric service use.

In conclusion, EDs may have not have received attention commensurate with the role they played after the terrorist attacks of September 11, 2001. These findings lend further urgency to the already pressing need to address what a recent Institute of Medicine report has called an "overburdened, under-funded and highly fragmented" system of emergency care. ${ }^{50}$ Compromise of the ED's ability to function in all of its multifaceted roles has important implications for the health and safety of the public. We suggest that, in the immediate postterrorist environment, EDs provide services beyond those directly aimed at life-threatening conditions and that affected populations may be expected to flock to these already overused care centers. Strengthening emergency services in general and the mental health services they provide in particular are aspects of disaster preparedness that deserve greater attention.

The role of EDs in responding to terrorism and disasters is clear. What is becoming increasingly apparent is the complexity of that role. To the best of our knowledge, this is the first report of a quantifiable increase in ED utilization for mental health services associated with physical proximity to terrorist attacks. Effective postterrorist interventions require the recognition that the behavioral and emotional consequences extend beyond those immediately affected and result in increased need for mental health services. EDs are a valuable resource in addressing those needs and deserve greater recognition and resources.

\section{Supervising editor: Debra E. Houry, MD, MPH}

Author contributions: CD, SG, and LDR all made substantive contributions to the study, and all endorse the data and conclusions. CD conceived and designed the study, received the funding, acquired the data, obtained institutional review board approval, and conducted the statistical analyses. CD, SG, and LDR interpreted the results, drafted the manuscript, and contributed to critical revisions for important intellectual content. CD takes responsibility for the paper as a whole.

Funding and support: By Annals policy, all authors are required to disclose any and all commercial, financial, and other relationships in any way related to the subject of this article, that may create any potential conflict of interest. See the Manuscript Submission Agreement in this issue for examples of specific conflicts covered by this statement. Supported by Centers for Disease Control and Prevention Health Protection Research Initiative grant No. 1 K01 CE000494-02. 
Publication dates: Received for publication August 3, 2006. Revision received October 4, 2006. Accepted for publication October 19, 2006. Available online December 4, 2006.

Address for reprints: Charles DiMaggio, PhD, MPH, PA-C, Columbia University Mailman School of Public Health, 722 West 168 Street, Rm r806, New York, NY 10032; 212-3426920, fax 212-305-9413; E-mail cjd11@columbia.edu.

\section{REFERENCES}

1. DiMaggio C, Galea S. The behavioral consequences of terrorism: a meta-analysis. Acad Emerg Med. 2006;13:559-566.

2. Galea S, Ahern J, Resnick H, et al. Psychological sequelae of the September 11 terrorist attacks in New York City. N Engl J Med. 2002;346:982-987.

3. Galea S, Resnick H, Ahern J, et al. Posttraumatic stress disorder in Manhattan, New York City, after the September 11th terrorist attacks. J Urban Health. 2002;79:340-353.

4. Chen $\mathrm{H}$, Chung $\mathrm{H}$, Chen $\mathrm{T}$, et al. The emotional distress in a community after the terrorist attack on the World Trade Center. Community Ment Health J. 2003;39:157-165.

5. Boscarino JA, Galea S, Adams RE, et al. Mental health service and medication use in New York City after the September 11, 2001, terrorist attack. Psychiatr Serv. 2004;55:274-283.

6. Fagan J, Galea S, Ahern J, et al. Relationship of self-reported asthma severity and urgent health care utilization to psychological sequelae of the September 11, 2001 terrorist attacks on the World Trade Center among New York City area residents. Psychosom Med. 2003;65:993-996.

7. Felton CJ. Project Liberty: a public health response to New Yorkers' mental health needs arising from the World Trade Center terrorist attacks. J Urban Health. 2002;79:429-433.

8. Moynihan PJ, Levine JM, Rodriguez O. The experiences of Project Liberty crisis counselors in the Bronx. Community Ment Health J. 2005;41:665-673.

9. Rudenstine S, Galea S, Ahern J, et al. Awareness and perceptions of a communitywide mental health program in New York City after September 11. Psychiatr Serv. 2003;54: 1404-1406.

10. Siegel C, Wanderling J, Laska E. Coping with disasters: estimation of additional capacity of the mental health sector to meet extended service demands. J Ment Health Policy Econ. 2004; 7:29-35.

11. Allegra JR, Mostashari F, Rothman J, et al. Cardiac events in New Jersey after the September 11, 2001, terrorist attack. J Urban Health. 2005;82:358-363.

12. Silver RC, Holman EA, Mclntosh DN, et al. Nationwide longitudinal study of psychological responses to September 11. JAMA. 2002; 288:1235-1244.

13. Stuber J, Galea S, Boscarino JA, et al. Was there unmet mental health need after the September 11, 2001 terrorist attacks? Soc Psychiatry Psychiatr Epidemiol. 2006;41:230-240.

14. Weissman EM, Kushner M, Marcus SM, et al. Volume of VA patients with posttraumatic stress disorder in the New York metropolitan area after September 11. Psychiatr Serv. 2003;54: 1641-1643.

15. Rosenheck R, Fontana A. Use of mental health services by veterans with PTSD after the terrorist attacks of September 11. Am J Psychiatry. 2003;160:1684-1690.

16. Rosenheck RA, Fontana A. Post-September 11 admission symptoms and treatment response among veterans with posttraumatic stress disorder. Psychiatr Serv. 2003;54: 1610-1617.

17. Satel SL. The mental health crisis that wasn't. Psychiatr Serv. 2003;54:1571.
18. Feeney JM, Goldberg R, Blumenthal JA, et al. September 11, 2001, revisited: a review of the data. Arch Surg. 2005;140: 1068-1073.

19. Fernandez WG, Galea S, Miller J, et al. Health status among emergency department patients approximately one year after consecutive disasters in New York City. Acad Emerg Med. 2005; 12:958-964

20. Wagner VL, Radigan MS, Roohan PJ, et al. Asthma in Medicaid managed care enrollees residing in New York City: results from a post-World Trade Center disaster survey. J Urban Health. 2005; 82:76-89.

21. Centers for Medicaid and Medicaid Services. Medicaid Analytic eXtract (MAX) General Information. Available at: http://www.cms.hhs.gov/MedicaidDataSourcesGenlnfo/ 07_MAXGenerallnformation.asp. Accessed May 23, 2006.

22. New York Department of Health. eMedNY Paper Forms. Available at: http://www.emedny.org/info/phase2/paper.html. Accessed September 29, 2006.

23. Centers for Medicaid and Medicaid Services. Medicaid Analytic eXtract (MAX) General Information. Available at: http://www.cms.hhs.gov/MedicaidDataSourcesGenlnfo/ 07_MAXGenerallnformation.asp. Accessed September 29, 2006.

24. Walkup JT, Boyer CA, Kellermann SL. Reliability of Medicaid claims files for use in psychiatric diagnoses and service delivery. Adm Policy Ment Health. 2000;27:129-139.

25. Centers for Medicaid and Medicaid Services. MAX data dictionaries and data elements ZIP file: Medicaid analytic extract (formerly SMRF) other services record data dictionary version 08/ 24/05. Available at: http://www.cms.hhs.gov/ MedicaidDataSourcesGenInfo/07_MAXGenerallnformation.asp. Accessed September 9, 2006.

26. Merriman K. Technical note: how to identify emergency room services in the Medicare claims data. Available at: http://www. resdac.umn.edu/Tools/tech_pubs.asp. Accessed September 29, 2006.

27. American Psychiatric Association. International Classification of Diseases, Ninth Revision, Clinical Modification: Physician ICD-9CM, 2005. Chicago, IL: AMA Press; 2004.

28. Wikipedia. Manhattan. Available at: http://en.wikipedia.org/wiki/ Manhattan. Accessed October 2, 2006.

29. Salsberry PJ, Chipps E, Kennedy C. Use of general medical services among Medicaid patients with severe and persistent mental illness. Psychiatr Serv. 2005;56:458-462.

30. US Public Health Service. Mental health: a report of the surgeon general. Available at: http://www.surgeongeneral.gov/library/ mentalhealth/chapter2/sec8.html. Accessed October 2, 2006.

31. Perry M. New York's Disaster Relief Medicaid: Insights and Implications for Covering Low-Income People. Washington, DC: Kaiser Commission on Medicaid and the Uninsured in Collaboration with the United Hospital Fund; 2002.

32. Calicchia M, Greene R, Lee E, et al. Disaster Relief Medicaid Evaluation Project. Ithaca, NY: Cornell University, School of Industrial and Labor Relations; 2005.

33. Moody-Williams JD, Krug S, O'Connor R, et al. Practice guidelines and performance measures in emergency medical services for children. Ann Emerg Med. 2002;39:404-412.

34. Research Data Assistance Center. Medicaid Data Available. Available at: http://www.resdac.umn.edu/Medicaid/ data_available.asp. Accessed November 15, 2006.

35. McCarter L, Goldman W. Use of psychotropics in two employee groups directly affected by the events of September 11. Psychiatr Serv. 2002;53:1366-1368.

36. Kettl $\mathrm{P}$, Bixler E. Changes in psychotropic drug use after September 11, 2001. Psychiatr Serv. 2002;53:1475-1476. 
37. Beare JM, Burrows D, Merrett JD. The effects of mental and physical stress on the incidence of skin disorders. $\mathrm{Br} J$ Dermatol. 1978;98:553-558.

38. Curran PS, Gregg W. Psychiatric aspects of terrorist violence in Northern Ireland (1969 to 1989). Med Leg J. 1990;58:83-96.

39. Burt CW, McCaig LF. Trends in hospital emergency department utilization: United States, 1992-99. Vital Health Stat 13. 2001:1-34.

40. McCaig LF, Burt CW. National Hospital Ambulatory Medical Care Survey: 2002 emergency department summary. Adv Data. 2004:1-34.

41. McCaig LF, Nawar EW. National Hospital Ambulatory Medical Care Survey: 2004 emergency department summary. Adv Data. 2006: 1-29.

42. Richardson LD, Asplin BR, Lowe RA. Emergency department crowding as a health policy issue: past development, future directions. Ann Emerg Med. 2002;40:388-393.

43. American College of Emergency Physicians. Positioning America's emergency health care system to respond to acts of terrorism: report of the Terrorism Response Task Force. Available at: http://www.acep.org/webportal/PracticeResources/issues/ disasters/masscas. Accessed July 21, 2006.

44. Fleischauer AT, Silk BJ, Schumacher M, et al. The validity of chief complaint and discharge diagnosis in emergency department-based syndromic surveillance. Acad Emerg Med. 2004;11:1262-1267.

45. Richardson LD, Hwang U. America's health care safety net: intact or unraveling? Acad Emerg Med. 2001;8:1056-1063.

46. Centers for Disease Control and Prevention. Injury and illness surveillance in hospitals and acute-care facilities after Hurricanes Katrina and Rita: New Orleans area, Louisiana, September 25-October 15, 2005. MMWR Morb Mortal Wkly Rep. 2006;55:35-38.

47. Saulny S. A legacy of the storm: depression and suicide. New York Times. June 21, 2006;1:1.

48. Norris FH, Friedman MJ, Watson PJ, et al. 60,000 Disaster victims speak, part I: an empirical review of the empirical literature, 1981-2001. Psychiatry. 2002;65:207-239.

49. Montazeri A, Baradaran H, Omidvari S, et al. Psychological distress among Bam earthquake survivors in Iran: a populationbased study. BMC Public Health. 2005;5:4. Available at: http:// www.biomedcentral.com/1471-2458/5/4. Accessed November 14, 2006.

50. Institute of Medicine. Hospital-based emergency care: at the breaking point. Available at: http://www.iom.edu. Accessed November 15, 2006. 